\title{
(2) \\ OPEN ACCESS \\ Effect of ischemic postconditioning on cell apoptosis and expression of relevant genes in non-culprit coronary arteries
}

\author{
Jian Wang (D), Song-Yuan He
}

Department of Cardiology, Aerospace Center Hospital, Peking University Aerospace School of Clinical Medicine, Beijing, China

\section{Correspondence to Dr Jian Wang, Department of Cardiology, Aerospace Center Hospital, Peking University Aerospace School of Clinical Medicine, Beijing 100049, China; 13671329282@139.com}

Accepted 23 June 2020 Published Online First 11 August 2020

\begin{abstract}
This study was performed to determine the effect of ischemic postconditioning on cell apoptosis and angiotensin II receptor type 1 (AT1), connexin $43(\mathrm{C} 43)$, and $\beta$-tubulin mRNA expression in non-culprit arteries. Non-culprit arterial tissues were isolated from a rabbit myocardial ischemiareperfusion model and randomly divided into sham, ischemia-reperfusion, and ischemic postconditioning groups. Cell apoptosis was detected by terminal deoxynucleotidyl transferase dUTP nick-end labeling (TUNEL) staining. Expression of angiotensin II, AT1, Cx43, and $\beta$-tubulin mRNA was evaluated by quantitative real-time polymerase chain reaction (qRT-PCR). TUNEL analysis indicated significantly higher ratios of apoptotic cells in the ischemia-reperfusion group than in the sham group. However, significantly fewer apoptotic cells were observed in the ischemic postconditioning group than in the ischemia-reperfusion group. The qRT-PCR results indicated significantly higher expression of AT1, Cx43, and $\beta$-tubulin mRNA in the ischemiareperfusion group than in the sham group. However, expression of AT1, Cx43, and $\beta$-tubulin was lower in the ischemic postconditioning group than in the ischemia-reperfusion group. The ratios of apoptotic cells and mRNA expression of AT1, $\mathrm{C} \times 43$, and $\beta$-tubulin in non-culprit arteries were increased after ischemia-reperfusion. Ischemic postconditioning may decrease these features and inhibit the progression of non-culprit arteries.
\end{abstract}

\section{INTRODUCTION}

The fundamental treatment strategy of ST-segment elevation myocardial infarction (STEMI) is the earliest possible restoration of myocardial perfusion. ${ }^{1}$ Primary percutaneous coronary intervention (PPCI) is the most efficient treatment for STEMI. PPCI has good success rates in restoring blood flow and low rates of infarction or recurrent ischemia, which significantly improves patients' quality of life and prevents further myocardial necrosis. ${ }^{2}{ }^{3}$ However, approximately $40 \%-65 \%$ of patients with STEMI present with three-vessel lesions. Additionally, recent clinical studies have shown that PPCI can lead to the progression of non-culprit lesions, which might be the

\section{Significance of this study}

What is already known about this subject?

- Primary percutaneous coronary intervention can lead to the progression of non-culprit lesions in patients with ST-segment elevation myocardial infarction, which might be the most significant factor influencing the prognosis after primary percutaneous coronary intervention.

- Non-culprit lesion progression can be affected by many factors, such as increased levels of catecholamines and activation of the angiotensin II/mitogen-activated protein kinase/connexin 43 (Agll/MAPK/ Cx43) pathway.

- Ischemic postconditioning may inhibit the Agll/MAPK/CX43 pathway and nonculprit lesion progression. However, the mechanism by which ischemic postconditioning affects the progression of non-culprit lesions has not been examined.

What are the new findings?

- The ratios of apoptotic cells and mRNA expression of Agll receptor type 1 (AT1), $\mathrm{Cx} 43$, and $\beta$-tubulin in non-culprit arteries were increased after ischemia-reperfusion.

- Ischemic postconditioning may decrease these features and inhibit the progression of non-culprit lesions.

How might these results change the focus of research or clinical practice?

- Apoptosis and mRNA expression of AT1, Cx43, and $\beta$-tubulin in non-culprit coronary arteries were increased after ischemia-reperfusion.

- Ischemic postconditioning may decrease apoptosis and the expression of these factors in non-culprit coronary arteries, thus inhibiting their pathological progression.

- In clinical practice, ischemic postconditioning may be used to inhibit non-culprit lesion progression.

most significant factor influencing the prognosis after PPCI. ${ }^{4}$ The molecular mechanisms of myocardial ischemia-reperfusion (IR) involve myocyte apoptosis, increased 


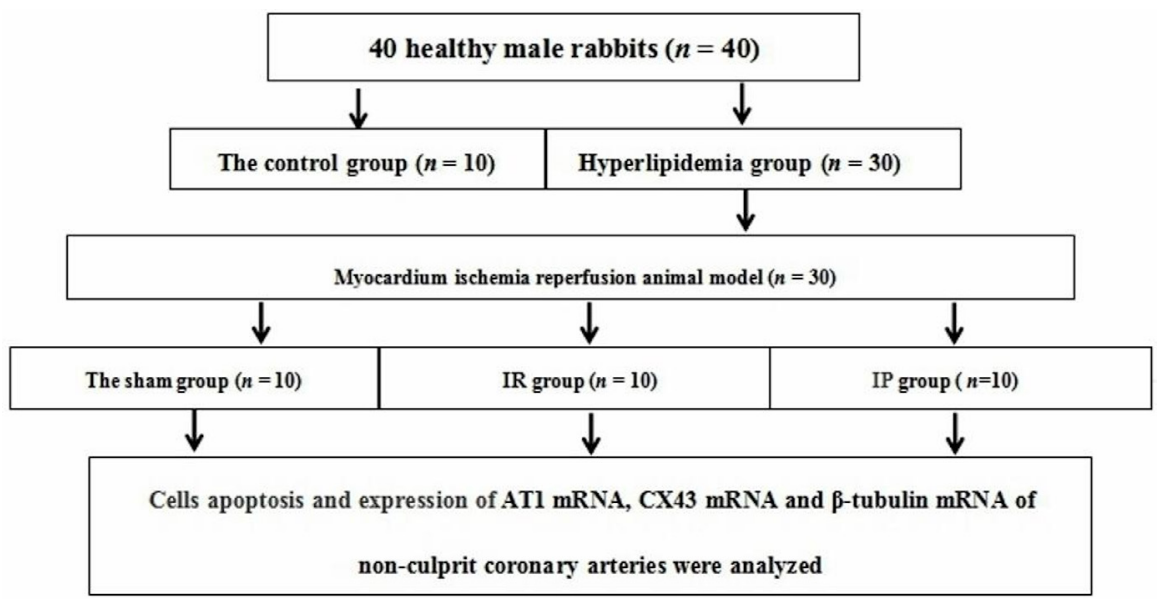

Figure 1 Experimental flowchart. IP group: ischemic postconditioning group; IR group: ischemia-reperfusion group.

catecholamine levels, and activation of the angiotensin II/mitogen-activated protein kinase/connexin 43 (AgII/ MAPK/Cx43) pathway. ${ }^{6}$ The reason for the progression of non-culprit lesions in patients with STEMI after PPCI is not clear, but chronic inflammation and sustained stress may be involved in the progression of non-culprit lesions. ${ }^{4}$ Our recent experimental study showed that nonculprit lesion progression can be affected by many factors, such as increased levels of catecholamines and activation of the AgII/MAPK/Cx43 pathway. ${ }^{6}$ In addition, Sun et $\mathrm{al}^{7}$ found that ischemic postconditioning (IP) may inhibit the AgII/MAPK/Cx43 pathway. Our recent clinical study ${ }^{8}$ showed that IP may inhibit non-culprit lesion progression. However, the mechanism by which IP affects the progression of non-culprit lesions has not been examined. We herein report the effect of IP on cell apoptosis and the expression of angiotensin II receptor type 1 (AT1), Cx43, and $\beta$-tubulin mRNA in non-culprit coronary arteries of rabbits.

\section{METHODS}

\section{Animal model of hyperlipidemia}

The requirement for informed consent in this study was exempted by the board. As shown in figure 1, 40 healthy male rabbits were randomly divided into a hyperlipidemia group $(n=30)$ and control group $(n=10)$. The rabbits in the hyperlipidemia group were fed a high-fat diet for 80 days, while the rabbits in the control group were fed a normal diet for 80 days. Auricular vein blood samples were taken on the 81 st day after a 12 hours fast. The serum was separated after centrifugation to measure the serum level of total cholesterol. Rabbits with a serum total cholesterol level of three times higher than the control group (1-2 mmol/L) were selected from the hyperlipidemia group and used for myocardial IR modeling.

\section{Animal model of myocardial IR}

An animal model of acute myocardial ischemia was prepared according to the following operation. Because of the long and steady maintenance of anesthesia, all rabbits were administered intraperitoneal anesthesia using urethane sodium at a dosage of $1 \mathrm{~g} / \mathrm{kg}$. In addition, all rabbits were administered $1 \mathrm{mg} / \mathrm{kg}$ of lidocaine to prevent ventricular fibrillation. In the control group, thoracotomy was performed on 10 hyperlipidemic rabbits without coronary artery ligation. Another 10 hyperlipidemic rabbits underwent thoracotomy alone. After exposing the pericardium and heart, the left anterior descending coronary artery (LAD) was clamped with 5/0 string and maintained for $30 \mathrm{~min}$. An electrocardiographic monitor was connected subcutaneously $(25 \mathrm{~mm} / \mathrm{s}, 10 \mathrm{ram} / \mathrm{mV})$. The model was defined as successfully prepared and thereafter maintained for $30 \mathrm{~min}$ under the following conditions: (1) ST elevation or necrotic Q wave observed in corresponding lead on the ECG and (2) dark purple myocardium in the corresponding region. After reperfusion was performed by releasing the clamp, the abdominal incisions were closed. All rabbits were fed a normal diet 1 week after the operation.

Experimental animal groups were as follows: sham group $(n=10$, thoracotomy without coronary artery ligation), IR group $(n=10$, thoracotomy, LAD ligation for $30 \mathrm{~min}$, and reperfusion for 1 week), and IP group $(n=10$, thoracotomy, LAD ligation for $30 \mathrm{~min}$, six cycles of $10 \mathrm{~s}$ reperfusion and $10 \mathrm{~s}$ ischemia, and reperfusion for 1 week).

\section{H\&E staining and observation}

Coronary arterial tissues were harvested for H\&E staining and observation. The tissues were embedded in paraffin, discontinuously and serially sectioned, stained with $\mathrm{H} \& \mathrm{E}$, and observed under a light microscope. The thickness of each section was $4 \mu \mathrm{m}$. All sections were analyzed with a medical imaging analysis system to measure the thickness of the plaques.

\section{Ratios of apoptotic cells in non-culprit coronary arterial tissues}

The right coronary arterial tissues were subsequently embedded in paraffin. The coronary arterial smooth muscle tissues were cut into $10-\mu \mathrm{m}$-thick slices with a freezing microtome and immediately fixed to a glass slide. The slices were stored at room temperature for $5 \mathrm{~min}$, fixed in 4\% paraformaldehyde, sealed with methanol solution containing $3 \%$ hydrogen peroxide, and immersed into $0.1 \%$ Triton $\mathrm{X}-100 \%$ and $0.1 \%$ sodium 
nitrate. The slices were then washed with $1 \times$ phosphatebuffered saline $(137 \mathrm{mmol} / \mathrm{L} \mathrm{NaCl}, 2.7 \mathrm{mmol} / \mathrm{L} \mathrm{KCl}$, $4.3 \mathrm{mmol} / \mathrm{L} \quad \mathrm{Na}_{2} \mathrm{HPO}_{4}$, and $1.4 \mathrm{mmol} / \mathrm{L} \quad \mathrm{KH}_{2} \mathrm{PO}_{4} ; \mathrm{pH}$ 7.4). Next, the slides were drained and blocked with goat serum for $30 \mathrm{~min}$ and then washed with $1 \times$ phosphatebuffered saline for $30 \mathrm{~min}$. The terminal deoxynucleotidyl transferase dUTP nick-end labeling (TUNEL) reaction solution was prepared by mixing an end-labeling enzyme and labeling the liquid at a ratio of 1:9. The slices were covered with the TUNEL reaction solution and incubated for $60 \mathrm{~min}$ in a moist chamber at $37^{\circ} \mathrm{C}$. Negative controls were incubated with labeling liquid without an end-labeling enzyme instead of the TUNEL reaction solution. Positive controls were incubated with DNaseI at a concentration of $5.1 \mathrm{U} / \mathrm{mL}$ for $10 \mathrm{~min}$ at room temperature before adding the TUNEL reaction solution. The samples were blocked with glycerol and observed using a fluorescence microscope (Olympus IX71; Olympus, Tokyo, Japan). Normal nuclei were labeled with blue fluorescence by 4',6-diamidino-2-phenylindole (DAPI) dye, whereas apoptotic nuclei were labeled with red fluorescence by the TUNEL reagent. Each sample was counted in at least three fields $(200 \times$ magnification). Apoptosis was determined by the number of positive nuclei per muscle cell. The ratio of apoptotic cells was obtained as the ratio of TUNEL-positive to DAPI-positive cells.

\section{Quantitative real-time polymerase chain reaction for expression of AT1, Cx43, and $\beta$-tubulin mRNA in non- culprit coronary arterial tissues}

TRIzol and chloroform reagents were used to extract total RNA from vascular smooth muscle cells according to the manufacturer's instructions. Briefly, after the addition of $2 \mathrm{~mL}$ of TRIzol reagent to lyse vascular smooth muscle cells for $20 \mathrm{~min}$, the sample was transferred to a $2 \mathrm{~mL}$ Eppendorf tube. Next, $400 \mu \mathrm{L}$ of chloroform was added. The tube was shaken vigorously for $30 \mathrm{~s}$ and allowed to stand for $15 \mathrm{~min}$. Next, the sample was centrifuged at $13,000 \times g$ for $15 \mathrm{~min}$ at $4^{\circ} \mathrm{C}$. The supernatant from the final extraction step was transferred to a clean $2 \mathrm{~mL}$ Eppendorf tube, in which RNA was precipitated with $500 \mu \mathrm{L}$ of isopropanol at $-20^{\circ} \mathrm{C}$ for $2 \mathrm{~h}$. Precipitated RNA was collected by centrifugation at $13,000 \times g$ for $15 \mathrm{~min}$ at $4^{\circ} \mathrm{C}$, and the pellet was washed with $1 \mathrm{~mL}$ of $75 \%$ ice-cold ethanol. The RNA pellet was resuspended in $20 \mu \mathrm{L}$ of nuclease-free water, and the two duplicate tubes were combined. The RNA concentration was measured using a spectrophotometer (Biolab ND-1000; Thermo Fisher Scientific, Waltham, MA, USA) at $260 \mathrm{~nm}$. RNA purity was assessed by determining the A260/A280 ratio. Purified RNA with an A260/A280 ratio of 1.7-2.0 was used in this study. Complimentary DNA was synthesized from RNA using reverse transcriptase and a PrimeScript reverse transcriptase kit (Cat. No. AB-1455/A, Fermentas; Thermo Fisher Scientific). Quantitative real-time polymerase chain reaction (qRT-PCR) was performed using a $20 \mu \mathrm{L}$ reaction volume containing $10 \mu \mathrm{L}$ of SYBR Premix Ex Taq II (Takara Bio, Otsu, Japan), $0.4 \mu \mathrm{L}$ of ROX Reference Dye II, $0.8 \mu \mathrm{L}$ each of forward and reverse primer (table 1), $2 \mu \mathrm{L}$ of complementary DNA, and $6 \mu \mathrm{L}$ of nuclease-free water. Reactions were run on a 7500 RT-PCR system (Thermo Fisher Scientific) for 45 cycles at $95^{\circ} \mathrm{C}$ for $15 \mathrm{~s}$, followed by $60^{\circ} \mathrm{C}$ for $1 \mathrm{~min}$. Specific PCR products were confirmed by melting-curve analysis with glyceraldehyde 3-phosphate dehydrogenase as an internal control. Gene expression levels were standardized against glyceraldehyde 3-phosphate dehydrogenase.

\section{Cx3 expression in smooth muscle cells in non-culprit arteries}

Smooth muscle cells from the four groups were separated, and total proteins were isolated from the smooth muscle cells. Equal amounts $(20 \mu \mathrm{g})$ of protein samples were then resolved by sodium dodecyl sulfate polyacrylamide gel electrophoresis and transferred onto a nitrocellulose membrane. The membrane was blocked in 5\% milk in Tris-buffered saline and $0.1 \%$ Tween 20 (TBS-T) for 1 hour and then incubated with primary antibody to $\mathrm{Cx} 43$ (1:200; USCN Life Science, Wuhan, China) or $\beta$-actin (1:200; USCN Life Science) as an internal control overnight at $4^{\circ} \mathrm{C}$, followed by incubation with horseradish peroxidase-conjugated secondary antibody (1:10,000; USCN Life Science) for 1 hour at $25^{\circ} \mathrm{C}$. After washing three times with TBS, the membrane was developed using an enhanced chemiluminescent detection system (Amersham Biosciences, Piscataway, New Jersey, USA). Signal intensities were quantitated using Quantity One software (Bio-Rad, Hercules, California, USA). Cx43 expression was quantitated by the $\mathrm{Cx} 43 / \beta$-actin optical absorption ratio.

\section{Statistical analysis}

Statistical analysis was performed using SPSS 20.0 statistical software (IBM, Armonk, New York, USA). Descriptive statistical data are expressed as mean \pm SD. Statistical significance was determined using one-way analysis of variance and the least significant difference test. $\mathrm{P}<0.05$ was considered statistically significant.

\section{RESULTS \\ H\&E staining of non-culprit arterial tissues}

H\&E staining indicated that the structures of non-culprit artery tissues were clear and that the alignment of vascular smooth muscle fibers was regular in each group. However,

Table 1 Primer sequences for RT-PCR

\begin{tabular}{llll}
\hline Gene name & GenBank accession no. & Forward primer 5'-3' & Reverse primer 5'-3' \\
\hline AT1 & NM_030985.4 & TCTGACATCGTGGACACTGC & CGTAGACAGGCTTGAGTGGG \\
Cx43 & NM_012567.2 & GACTGCTTCCTCTCACGTCC & CGCGATCCTTAACGCCTTG \\
-tubulin & NM_139254.2 & CTGCTCATCAGCAAAGTGCG & TGCGGAAGCAGATGTCGTAG \\
\hline
\end{tabular}




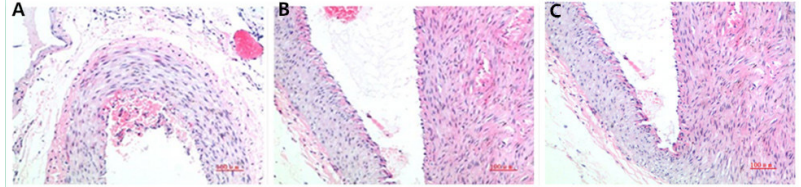

Figure 2 H\&E staining of non-culprit arterial tissues (400x). (A) Sham group. (B) Ischemia-reperfusion group. (C) Ischemic postconditioning group.

significant atherosclerotic plaques were present in the IR and IP groups compared with the sham group (figure 2).

\section{Ratios of apoptotic cells in non-culprit coronary arterial tissues}

As shown in figure 3, a higher ratio of apoptotic cells was observed in non-culprit coronary arterial tissues of the IR group than sham group $(46.11 \pm 5.92$ vs $3.77 \pm 6.31$, $\mathrm{p}<0.001)$. However, a lower ratio of apoptotic cells was observed in non-culprit coronary arterial tissues in the IP group than IR group $(28.36 \pm 9.41$ vs $46.11 \pm 5.92$, $\mathrm{p}<0.001)$.

\section{AT1, Cx43, and $\beta$-tubulin mRNA expression in non-culprit coronary arterial tissues}

Expression of AT1 (30.576 \pm 1.760 vs $1.002 \pm 0.068$, $\mathrm{p}<0.01), \mathrm{Cx} 43(15.171 \pm 1.736$ vs $1.009 \pm 0.133, \mathrm{p}<0.01)$, and $\beta$-tubulin $(1.361 \pm 0.042$ vs $1.003 \pm 0.083, \mathrm{p}<0.01)$ mRNA in the IR group was significantly higher than that in the sham group. However, expression of AT1 (4.697 \pm 0.227 vs $30.576 \pm 1.760, \mathrm{p}<0.01), \mathrm{Cx} 43 \quad(2.267 \pm 0.312$ vs $15.171 \pm 1.736, \mathrm{p}<0.01)$, and $\beta$-tubulin $(1.083 \pm 0.098$ vs $1.361 \pm 0.042, \mathrm{p}<0.01) \mathrm{mRNA}$ was significantly lower in the IP than IR group (figure 4).

Expression of $\mathrm{Cx} 43$ protein was significantly higher in the IR than sham group $(1.69 \pm 0.21$ vs $1.05 \pm 0.11$, $p<0.0001)$. However, expression of $\mathrm{Cx} 43$ protein was significantly lower in the IP than IR group $(0.81 \pm 0.15$ vs $1.69 \pm 0.21$, $\mathrm{p}<0.0001$ ) (table 2, figure 5).

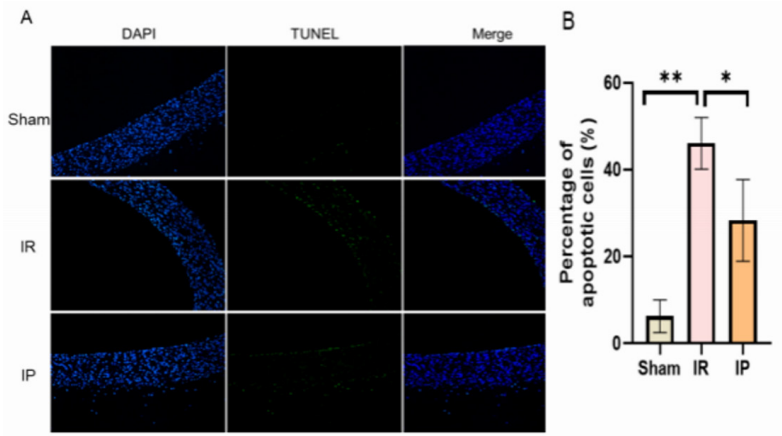

Figure 3 Effect of IP on the apoptotic cells in non-culprit coronary arterial tissues. (A) TUNEL and DAPI staining of nonculprit arterial tissues. (B) Percentage of apoptotic cells in each group. $n=10$ /group. * $P<0.05$ and ${ }^{*} p<0.01$. DAPI, 4',6-diamidino2-phenylindole; IP, ischemic postconditioning; IR, ischemiareperfusion; TUNEL, terminal deoxynucleotidyl transferase dUTP nick-end labeling.
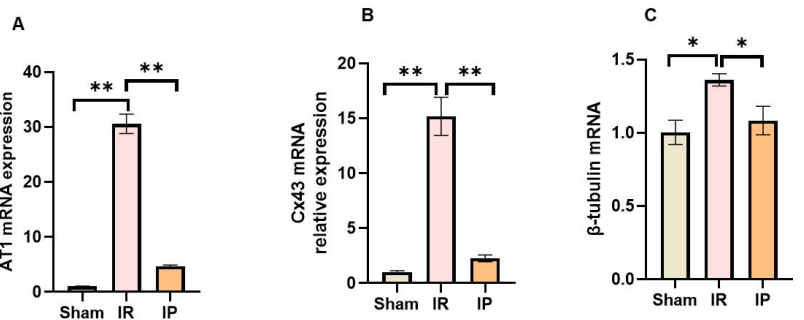

Figure 4 Effect of IP on the mRNA expression of AT1, Cx43, and $\beta$-tubulin in non-culprit coronary arterial tissues. $n=10 /$ group. ${ }^{*} \mathrm{P}<0.05$ and ${ }^{*} \mathrm{p}<0.01$. AT1, angiotensin II receptor type 1; Cx43, connexin 43; IP, ischemic postconditioning; IR, ischemiareperfusion.

\section{DISCUSSION}

PPCI in a culprit artery is the preferred strategy for the treatment of patients with acute STEMI. However, approximately $40 \%-65 \%$ of patients with STEMI present with three-vessel lesions. A clinical follow-up study of such patients after successful PPCI suggested that non-culprit lesions may progress, which may be the most important factor influencing the prognosis of patients with acute myocardial infarction after successful PPCI. ${ }^{4}$

Few studies have examined the progression of non-culprit lesions. Hanratty et $a l^{9}$ demonstrated exaggeration of nonculprit lesions during acute myocardial infarction and indicated that inflammatory and spastic mechanisms may be involved in non-culprit lesion progression. On follow-up angiography of 117 patients with acute coronary syndrome, Tsiamis et $a l^{10}$ found that non-culprit lesions may progress and that acute myocardial infarction may be an independent predictive factor for this progression. Our previous study $^{11}$ suggested that non-culprit lesion progression may be the most important prognostic factor in patients with STEMI after successful PPCI. This indicates that inflammation and stress might contribute to the progression of nonculprit lesions. In addition, the AgII-MAPK-Cx43 pathway might be involved in the progression of non-culprit lesions according to the findings in a rabbit model of IR. ${ }^{6}$ Sun et $a l^{7}$ demonstrated that IP can inhibit the MAPK-Cx43 pathway, indicating that IP may inhibit non-culprit lesion progression.

In the present study, we investigated the effect of IP on cell apoptosis and mRNA expression of AT1, Cx43, $\beta$-tubulin, and $\mathrm{Cx} 43$ protein in non-culprit coronary arteries of a rabbit IR model. H\&E staining of non-culprit arterial tissues showed that the structures of the non-culprit arterial tissues were clear and that the alignment of vascular smooth muscle fibers was regular in each group. There were no significant pathological changes in the IR or IP group compared with the sham group (figure 1).

Quantitative analysis of apoptosis in non-culprit coronary arterial tissues indicated significantly higher ratios of apoptotic cells in the IR than sham group $(46.11 \pm 5.92$ vs $3.77 \pm 6.31, \mathrm{p}<0.001)$. Moreover, the ratios of apoptotic cells were significantly lower in the IP than IR group $(28.36 \pm 9.41$ vs $46.11 \pm 5.92, \mathrm{p}<0.001)$. These results suggest that IR may increase cell apoptosis in non-culprit coronary arterial tissues and that IP may prevent nonculprit lesion progression by inhibiting this apoptosis. 
Table 2 Effect of IP on the expression of Cx43 in non-culprit coronary arterial tissues (Cx43/ $\beta$-actin optical absorption ratio)

\begin{tabular}{lllll}
\hline $\mathrm{n}=10$ & The control group & The sham group & IR group & IP group \\
\hline Cx43/ $\beta$-actin optical absorption ratio & $0.51 \pm 0.13$ & $1.05 \pm 0.11^{*}$ & $1.69 \pm 0.21 \dagger$ & $0.81 \pm 0.15 \neq$ \\
\hline
\end{tabular}

${ }^{*}$ Compared with normal control group, $p<0.0001$.

tCompared with the sham group, $p<0.0001$.

$\neq$ Compared with IR group, $\mathrm{p}<0.0001$.

Cx43, connexin 43; IP, ischemic postconditioning; IR, ischemia-reperfusion.

Quantitative analysis of AT1, Cx43, and $\beta$-tubulin mRNA expression in non-culprit coronary arterial tissues indicated higher expression of AT1 and $\beta$-tubulin in the IR than sham group. In addition, lower expression of AT1 and $\beta$-tubulin mRNA was observed in the IP than IR group. These results indicate that AT1, Cx43, and $\beta$-tubulin may participate in the progression of non-culprit lesions and that IP may prevent this progression by inhibiting mRNA expression of AT1, Cx43, and $\beta$-tubulin and activation of the AgIIMAPK-Cx43- $\beta$-tubulin pathway in non-culprit coronary arterial tissues. ${ }^{11-14}$

We observed lower mRNA expression of AT1, Cx43, $\beta$-tubulin, and $\mathrm{Cx} 43$ protein in non-culprit coronary arteries in the IP than IR group. However, He et $a^{15}$ found that IP increased $\mathrm{Cx} 43$ expression in the left ventricular myocardial cellular membrane and attenuated reperfusion injury in a rat model of acute myocardial infarction. Although this result was not in conflict with our findings, He et al ${ }^{15}$ investigated the role of IP on $\mathrm{Cx} 43$ expression in the left ventricular myocardial cellular membrane during an early stage (1 and 3 hour after reperfusion), whereas we investigated the role of IP on expression of non-culprit coronary arteries at a later stage (1 week after reperfusion).

Schulz et $a l^{16}$ reported that in contrast to its importance for ischemic or pharmacological preconditioning, Cx43 does not impact the cardioprotection achieved by IP. The results of their study also implicated a role for IP on Cx43 expression in the left ventricular myocardial cellular membrane during the early stage, which is not in conflict with our findings.

$\mathrm{Cx} 43$ is present in the cell membrane and in mitochondria. Indeed, $\mathrm{Cx} 43$ in the inner mitochondrial membrane may participate in functional coordination between subsarcolemmal and interfibrillar mitochondria. $\mathrm{Cx} 43$ in the subsarcolemmal mitochondria is involved in regulation of reactive oxygen species production through modulation of potassium permeability and oxidative phosphorylation. Notably, subsarcolemmal mitochondria appear to play a prominent role in superoxide production. In addition, $\mathrm{Cx} 43$

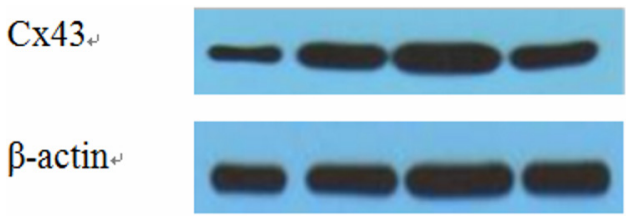

Figure 5 Effect of ischemic postconditioning (IP) on the expression of $\mathrm{Cx} 43$ in non-culprit coronary arterial tissues. $n=10$ / group. From left to right: normal control group, sham group, IR group, IP group. Cx43, connexin 43; IP, ischemic postconditioning; $\mathrm{IR}$, ischemia-reperfusion. in subsarcolemmal mitochondria is involved in calcium uptake from the sarcoplasmic reticulum and antioxidant regeneration. In contrast, interfibrillar mitochondria are important players in energy demand-supply matching, cytosolic calcium buffering, and antioxidant regeneration as a result of their intimate communication with the sarcoplasmic reticulum. In the present study, we aimed to determine the effect of IP on cell apoptosis and mRNA expression of AT1, Cx43, $\beta$-tubulin, and $\mathrm{Cx} 43$ protein in non-culprit coronary arteries of rabbits. As such, differences in the distribution and function of $\mathrm{Cx} 43$ in various cellular locations, as well as the role of individual mitochondrial subpopulations, should be investigated in future studies.

In our recent study, we investigated the expression of $\beta$-tubulin in non-culprit arteries and the effect of ramipril on lesion progression. Our results indicated that a sympathetic nervous system catecholamine/AgII/Cx43/ $\beta$-tubulin pathway may participate in the progression of non-culprit lesions ${ }^{15}$. In this study, we also found increased expression of AT1, Cx43, and $\beta$-tubulin mRNA in non-culprit coronary arteries after IR. IP may decrease the ratio of apoptotic cells and expression of AT1, Cx43, and $\beta$-tubulin mRNA in non-culprit coronary arteries, thus inhibiting non-culprit lesion progression. Moreover, our results indicated that IP inhibited the sympathetic catecholamine/AgII/Cx43/ $\beta$-tubulin pathway.

\section{CONCLUSION}

Apoptosis and mRNA expression of AT1, Cx43, and $\beta$-tubulin in non-culprit coronary arteries were increased after IR. However, IP may decrease apoptosis and expression of these factors in non-culprit coronary arteries, thus inhibiting their pathological progression. In clinical practice, IP may be used to inhibit non-culprit lesion progression.

Acknowledgements We thank Liwen Bianji, Edanz Group China (http:// www.liwenbianji.cn/ac), for editing the English text of a draft of this manuscript.

Contributors JW designed and coordinated the study, JW wrote the main manuscript text, S-YH collected samples. All authors reviewed the manuscript.

Funding The study was supported by the Natural Science Foundation of Qinghai Province (2019-ZJ-929).

Competing interests None declared.

Patient consent for publication Not required.

Ethics approval This study conformed to the ethical guidelines of the 1975 Declaration of Helsinki as reflected by a priori approval by the Ethics Committee of Peking University (Beijing, China), and the study protocol was approved by the Institutional Ethics Committee of Peking University.

Provenance and peer review Not commissioned; externally peer reviewed.

Data availability statement Data are available on reasonable request. All data were available in database of Aerospace Center Hospital, Peking University Aerospace School of Clinical Medicine. 
Open access This is an open access article distributed in accordance with the Creative Commons Attribution Non Commercial (CC BY-NC 4.0) license, which permits others to distribute, remix, adapt, build upon this work noncommercially, and license their derivative works on different terms, provided the original work is properly cited, an indication of whether changes were made, and the use is non-commercial. See: http://creativecommons.org/ licenses/by-nc/4.0/.

\section{ORCID iD}

Jian Wang http://orcid.org/0000-0001-5249-2252

\section{REFERENCES}

1 Wong DTL, Puri R, Psaltis PJ, et al. Acute ST-segment myocardial infarctionevolution of treatment strategies. World J Cardiovasc Dis 2013;03:551-60.

2 Levine GN, Bates ER, Blankenship JC, et al. 2011 ACCF/AHA/SCAl guideline for percutaneous coronary intervention. A report of the American College of cardiology Foundation/American heart association Task force on practice guidelines and the Society for cardiovascular angiography and interventions. J Am Coll Cardiol 2011;58:e44-122.

3 O'Gara PT, Kushner FG, Ascheim DD, et al. 2013 ACCF/AHA guideline for the management of ST-elevation myocardial infarction: executive summary: a report of the American College of cardiology Foundation/American heart association Task force on practice guidelines. J Am Coll Cardiol 2013:61:485-510.

4 Wang J, Liu J-hua, Zhu X-ling, Zhu XL, et al. Nonculprit lesion progression in patients with ST elevation myocardial infarction after primary percutaneous coronary intervention. Int Heart J 2014;55:48-52.

5 Jeehoon K, Woo PK, Lee MS, et al. The natural course of nonculprit coronary artery lesions; analysis by serial quantitative coronary angiography. $B M C$ Musculoskelet Disord 2018;18.
6 Wang J, CX L, Liu JH, et al. Expression of connexin 43 in nonÂ.infarction related coronary arteries and stimulation mechanism of angiotensin II in animal model of acute ST elevation myocardial infarction. Chin Med 2015:10:793-6.

7 Sun J, Ren FX, Sun XJ, et al. Effects of ischemic postconditioning on p38MAPK and PLA expression in rats with myocardial ischemia reperfusion injury. Chin Circ J 2018;33:611-5.

8 Wang J, Huang YS, Wei JH, et al. Preventive effect of ischemic postconditioning on non-culprit lesion progression in patients with acute myocardial infarction after priamry percutaneous coronary intervention. Chin Med 2018;13:805-9.

9 Hanratty CG, Koyama Y, Rasmussen HH, et al. Exaggeration of nonculprit stenosis severity during acute myocardial infarction: implications for immediate multivessel revascularization. J Am Coll Cardiol 2002;40:911-6.

10 Tsiamis E, Toutouzas K, Synetos A, et al. Prognostic clinical and angiographic characteristics for the development of a new significant lesion in remote segments after successful percutaneous coronary intervention. Int I Cardiol 2010;143:29-34.

11 Wang J, Liu J-hua, Zheng B, et al. Impact of primary percutaneous coronary intervention on blood perfusion in nonculprit artery in patients with anterior ST elevation myocardial infarction. Chin Med J 2013;126:22-6.

12 Wang J, Li Z-X, Liu J-H, et al. Different expression of connexin 43 between culprit arteries and non-culprit arteries and role of angiotensin II on expression of connexin 43 in non-culprit arteries. Int J Clin Exp Pathol 2018;11:382-90.

13 Wang J, Liu JH, Wang SP, et al. Expression of $\hat{I}^{2}$-tubulin in non-culprit arteries and effect of ramipril on lesion progression. Int I Clin Exp Med 2018;11:13639-44.

14 Pfenniger A, Chanson M, Kwak BR. Connexins in atherosclerosis. Biochim Biophys Acta 2013;1828:157-66.

$15 \mathrm{He} \mathrm{H}$, Li N, Zhao Z, et al. Ischemic postconditioning improves the expression of cellular membrane connexin 43 and attenuates the reperfusion injury in rat acute myocardial infarction. Biomed Rep 2015;3:668-74.

16 Schulz R, Boengler K, Totzeck A, et al. Connexin 43 in ischemic pre- and postconditioning. Heart Fail Rev 2007;12:261-6. 